\title{
Predictors of Implantable Pulse Generator Placement After Sacral Neuromodulation: Who Does Better?
}

\section{Jennifer T. Anger, MD, MPH*; Anne P. Cameron, MD; Rodger Madison, MA;; Christopher Saigal, MD, MPH; j. Quentin Clemens, MD, MSCI ; Urologic Diseases in America Project}

\begin{abstract}
Objectives: Numerous studies have documented a relationship between provider variables, including surgeon volume and specialty, and outcomes for surgical procedures. In this study we analyzed claims data from a Medicare database to analyze outcomes of sacral neuromodulation (SNM) with respect to both provider and patient factors.

Materials and Methods: A 5\% random sample of Medicare beneficiaries from 1997 to 2007 was the data source. Data retrieved included demographic information, ICD-9 diagnosis codes, and CPT procedure codes. Multivariate analysis was performed to identify predictors of progression to implantable pulse generator (IPG) implantation.

Results: After stage I testing, urologists were more likely than gynecologists to proceed to IPG placement (Center for Medicare and Medicaid Services: $49 \%$ vs. $43 \%, p<0.0001)$. After percutaneous testing, gynecologists were more likely than urologists to proceed to battery placement ( $63 \%$ vs.44\%, $p=0.005$ ). Among the patient variables analyzed, women were more likely than men to progress to battery placement. Patients treated by high-volume providers had higher rates of IPG placement after formal stage I trials $(71 \%$ vs. $33 \%, p<0.0001)$.

Conclusions: The rate of IPG implantation after SNM was greater among high-volume providers. Women had better outcomes than men. Further research may better define the relationship between outcomes of sacral neuromodulation and specific etiology of voiding dysfunction.
\end{abstract}

Keywords: Claims data, InterStim, provider specialty, provider volume

Conflict of Interest: The authors reported no conflict of interest.

\section{INTRODUCTION}

Numerous studies have documented a relationship between provider variables, including surgeon volume and specialty, and outcomes for surgical procedures. Volume, or case load, has been used as a surrogate for quality of care in many diseases and is easily abstracted and analyzed. Studies evaluating postoperative morbidity and mortality have shown that high-volume hospitals offer better outcomes for vascular surgery, liver transplantation, and major cancer surgery (1-4). The urologic literature has also demonstrated that the rates of postoperative and late urinary complications after radical prostatectomy are significantly reduced if the procedure is performed in a high-volume hospital and by a surgeon who performs a large number of such procedures (5-8).

Surgeon specialty has also been shown to have an effect on outcomes (9-11). McKenna et al. demonstrated that patients who underwent surgical excision of cutaneous melanoma by a dermatologist or a surgical oncologist had lower recurrence rates than those who had their excision by a general surgeon (11). In a Medicare claims analysis of pubovaginal sling outcomes, we previously found that gynecologists were more likely than urologists to perform concomitant prolapse surgery, thereby reducing early re-operation rates for prolapse (12).
Sacral neuromodulation (SNM) is Food and Drug Administrationapproved for many types of voiding dysfunction refractory to medical therapy. It involves the placement of a small lead in the third sacral foramen, adjacent to the S3 nerve root, connected to an implantable pulse generator (IPG) placed in the buttock area (13). It serves as a bladder "pacemaker" that modulates S3-related neural pathways and improves voiding dysfunction of many etiologies,

Address Correspondence to: Jennifer T. Anger, MD, MPH, Urological Research, Associate Professor of Urology, Cedars-Sinai Medica Center, 99 N. La Cienega Blvd., \#307, Beverly Hills, CA 90211, USA. Email: angerj@cshs.org

* Division of Urology, Cedars-Sinai Medical Center, Los Angeles, CA, USA;

+ Department of Urology, University of Michigan, Ann Arbor, MI, USA;

‡ RAND Corporation, Santa Monica, CA, USA; and

$\S$ Department of Urology, University of California, Los Angeles, Los Angeles, CA, USA

For more information on author guidelines, an explanation of our peer review process, and conflict of interest informed consent policies, please go to http:// www.wiley.com/bw/submit.asp?ref=1094-7159\&site=1

Funded by the National Institute of Diabetes and Digestive and Kidney Diseases as part of the Urologic Diseases in America Project.

Supplementary material for this article can be obtained at http://www udaonline.net. 
including overactive bladder symptoms (both "wet" and "dry"), urinary retention, and pelvic pain associated with urinary frequency. Patients undergo a short (one- to two-week) period of testing before proceeding with permanent pulse generator placement. Testing can either be with a permanent lead (formal stage I testing) or a temporary wire that is then replaced with a permanent lead after the testing period (percutaneous test) (13).

In order to understand patterns of care for patients undergoing SNM for various types of voiding disorders, we recently analyzed data from a $5 \%$ random sample of Medicare beneficiaries (13). In this analysis, we specifically sought to evaluate the differences in rates of IPG implantation with respect to both provider specialty and volume. We also analyzed patient variables, including age, gender, race, and chief diagnosis for which SNM was performed.

\section{MATERIALS AND METHODS}

Medicare claims provide the billing information of claims for services among Medicare beneficiaries in the United States. We obtained Medicare claims data from the Center for Medicare and Medicaid Services Public Use Files, as previously described (13). We used a $5 \%$ national random sample of Medicare beneficiaries from 1997 to 2007. Previous studies provide internal validation for similar research using 5\% Medicare public use administrative data (14-16). Each patient was linked by a unique patient identifier. All patients were therefore de-identified, and this work was granted an institutional review board exemption from the University of California, Los Angeles and RAND. CPT codes identified relevant procedures performed on each individual, and ICD-9 diagnosis codes identified the indication, as previously described (13). We categorized patients with overactive bladder (OAB)-dry as those diagnosed with either urgency of urination (ICD-9 code 788.63), urinary frequency (788.41), bladder hypertonicity (596.51), detrusor instability (596.59), or nocturia (788.43). Those with OAB-wet included patients with a diagnosis of unspecified urinary incontinence (788.30), urge incontinence (788.31), and mixed incontinence (788.33). Patients were also grouped into neurogenic voiding dysfunction, interstitial cystitis, or "other" voiding dysfunction categories, according to relevant diagnosis codes (13).

Lead placement was categorized into percutaneous lead placement (CPT-4 code 64561) and operative lead placement (stage I, CPT-4 code 64581). Implantation was defined as a patient proceeding to battery implantation (CPT-4 code 64590). We compared out- comes by provider volume and specialty (urology vs. gynecology). All implanting physicians were stratified based on number of cases performed over the 1997-2007 time period. High-volume providers were defined as those who were in the upper 25th percentile of number of procedures performed, which corresponded to 5+ procedures. Descriptive statistics were used to report IPG implantation rates. Patient variables analyzed included age, gender, race, and chief diagnosis for which SNM was performed. Multivariate analysis was performed to control for covariates and identify predictors of outcomes. The chi-square test was used to compare implantation rates based on the patient and provider variables. Statistical analysis was performed using Statistical Analysis System $\left(\mathrm{SAS}^{\circledR}\right)$.

\section{RESULTS}

In the 1997-2007 5\% Medicare sample, 1132 patients underwent staged (operative) lead placement for test stimulation, and 358 underwent percutaneous test stimulation. Caucasians represented $91.3 \%$ of patients, and $73.6 \%$ were female (13); $35.4 \%$ of the staged tests and $45.8 \%$ of the percutaneous tests were found to be successful, as defined by proceeding to battery implantation (13).

The most common associated ICD-9 diagnosis code was "wet" or "dry" OAB (63.0\%), followed by "other" indications (21.7\%), urinary retention (9.5\%), neurogenic bladder (3.2\%), and interstitial cystitis (2.6\%). Forty-six percent of the percutaneous tests and $35.4 \%$ of the staged tests resulted in placement of a permanent IPG. Implantation rates were greater in women than in men $(43.7 \%$ vs. $29.3 \%, p<$ 0.0001 ). As previously described, patients underwent reprogramming an average of 2.15 times in their first year, with that number decreasing over subsequent years. Of 558 batteries implanted, 63 (11.3\%) were explanted (17).

The top quartile for procedure volume was at least five cases in 10 years. Physicians in the top quartile performed $35.1 \%$ of all cases (176 percutaneous trials and 240 operative trials) and those in the lower three quartiles performed $64.9 \%$ of cases (174 percutaneous trials and 595 operative trials). In multivariate analysis, physicians in the top quartile were more likely to progress to IPG placement than those in the lower three quartiles (Table 1). Urologists performed $64.7 \%$ of cases (305 percutaneous trials and 670 operative trials), and $13.9 \%$ were performed by gynecologists (49 percutaneous trials and 161 operative trials). Urologists had better outcomes after operative trials (higher rates of IPG placement) than gynecologists in both datasets (49\% vs. $43 \%, p<0.0001)$. However, gynecologists

Table 1. Conversion Rate of Sacral Neuromodulation by Provider Volume in a 5\% Sample of Medicare Beneficiaries, $1997-2007$.

\begin{tabular}{|c|c|c|c|c|c|c|c|c|c|c|c|}
\hline \multirow[t]{2}{*}{ Provider } & \multirow{2}{*}{$\begin{array}{l}\text { Percutaneous } \\
\text { test } \\
\text { Number of } \\
\text { percutaneous } \\
\text { tests }\end{array}$} & \multirow[b]{2}{*}{$\begin{array}{l}\text { Successful } \\
(\%)\end{array}$} & \multirow[b]{2}{*}{$\begin{array}{l}\text { Failed (\%) } \\
\text { No two-stage }\end{array}$} & \multirow[b]{2}{*}{$\begin{array}{l}\text { Successful } \\
\text { two-stage }\end{array}$} & \multirow[b]{2}{*}{$\begin{array}{l}\text { Failed } \\
\text { two-stage }\end{array}$} & \multirow[b]{2}{*}{$p$ value } & \multicolumn{3}{|c|}{$\begin{array}{l}\text { No percutaneous } \\
\text { test }\end{array}$} & \multirow[b]{2}{*}{$p$ value } & \multirow{2}{*}{$\begin{array}{l}\text { Overall } \\
\text { success } \\
\text { rate (\%) }\end{array}$} \\
\hline & & & & & & & $\begin{array}{l}\text { Number of } \\
\text { two-stage } \\
\text { tests }\end{array}$ & $\begin{array}{l}\text { Successful } \\
\text { two-stage } \\
(\%)\end{array}$ & $\begin{array}{l}\text { Failed } \\
\text { two-stage } \\
(\%)\end{array}$ & & \\
\hline \multicolumn{12}{|l|}{ Specialty } \\
\hline Urologist & 305 & 44.3 & 45.6 & 6.9 & 3.3 & 0.0046 & 670 & 46.2 & 50.6 & $<0.0001$ & 48.8 \\
\hline Gynecologist & 49 & 63.2 & 34.7 & 0 & 2.0 & & 161 & 37.3 & 62.7 & & 43.3 \\
\hline Other & 12 & 8.3 & 91.7 & 0 & 0 & & 311 & 11.3 & 88.7 & & 11.1 \\
\hline Total & 366 & 45.6 & 45.6 & 5.7 & 3.0 & & 1142 & 35.5 & 62.7 & & 39.9 \\
\hline \multicolumn{12}{|l|}{ Volume } \\
\hline High & 176 & 43.2 & 48.3 & 5.7 & 2.8 & 0.6937 & 240 & 71.3 & 24.6 & $<0.0001$ & 63.3 \\
\hline Low & 174 & 48.9 & 42.0 & 6.3 & 2.9 & & 595 & 33.1 & 65.0 & & 38.7 \\
\hline Total & 350 & 46.0 & 45.1 & 6.0 & 2.9 & & 835 & 44.1 & 53.4 & & 47.3 \\
\hline
\end{tabular}


Table 2. Multivariate Analysis of Outcomes Based on Provider and Patient Variables.

\begin{tabular}{|c|c|c|c|c|c|c|c|c|c|}
\hline \multirow{3}{*}{$\begin{array}{l}\text { Measured variable } \\
\text { High surgeon volume vs. low }\end{array}$} & \multicolumn{3}{|c|}{ Successful percutaneous test } & \multicolumn{3}{|c|}{ Successful two-stage, no percutaneous test } & \multicolumn{3}{|c|}{ Overall success } \\
\hline & \multirow{2}{*}{$\begin{array}{l}\text { Odds ratio } \\
0.768\end{array}$} & \multicolumn{2}{|c|}{$95 \% \mathrm{Cl}$} & \multirow{2}{*}{$\begin{array}{l}\text { Odds ratio } \\
5.019\end{array}$} & \multicolumn{2}{|c|}{$95 \% \mathrm{Cl}$} & \multirow{2}{*}{$\begin{array}{l}\text { Odds ratio } \\
2.743\end{array}$} & \multicolumn{2}{|l|}{$95 \% \mathrm{Cl}$} \\
\hline & & 0.476 & 1.241 & & 3.573 & 7.050 & & 2.123 & 3.543 \\
\hline Urologist vs. gynecologist & 0.749 & 0.387 & 1.451 & 1.470 & 0.999 & 2.162 & 1.575 & 1.149 & 2.160 \\
\hline Female vs. male & 2.882 & 1.566 & 5.305 & 1.620 & 1.108 & 2.368 & 1.861 & 1.379 & 2.512 \\
\hline $\begin{array}{c}\text { Age } 55 \text { or less vs. older than } 55 \\
\text { Other diagnoses vs. wet } \\
\text { overactive bladder }\end{array}$ & 0.108 & 0.054 & 0.215 & 2.036 & 1.488 & 2.786 & 1.042 & 0.805 & 1.347 \\
\hline Interstitial cystitis & 1.913 & 0.435 & 8.414 & 0.416 & 0.173 & 1.002 & 0.829 & 0.412 & 1.670 \\
\hline Urinary retention & 0.807 & 0.401 & 1.624 & 0.925 & 0.565 & 1.514 & 0.967 & 0.656 & 1.427 \\
\hline Dry overactive bladder & 0.615 & 0.348 & 1.089 & 0.786 & 0.552 & 1.119 & 0.731 & 0.551 & 0.971 \\
\hline
\end{tabular}

Odds ratio (OR) measures the effect size of the measured variable. OR $>1$ means better success than comparison group, and OR $<1$ means less success. The magnitude of the OR correlates with the strength of the association (i.e., the bigger the OR, the greater the effect of the measured variable).

A 95\% confidence interval (CI) that crosses 1 is not considered statistically significant.

had better outcomes of percutaneous testing $(63 \%$ vs. $44 \%, p=$ $0.005)$. Multivariate analysis confirmed a higher rate of IPG placement overall among urologists (Table 2).

IPG implantation rates were greater among female patients than male patients ( 41.6 vs. $27.7 \%, p<0.0001$ ), and multivariate analysis confirmed a nearly twofold difference in outcomes between sexes. Patients with OAB-dry had worse overall outcomes than those with OAB-wet. Older patients ( $>55$ years) had a lower rate of IPG implantation after formal staged trials but a higher rate of IPG placement after percutaneous trial.

\section{DISCUSSION}

This Medicare 5\% sample identified a relationship between provider variables and conversion rates, as measured by proceeding to IPG implantation. Patients who underwent surgical placement of a lead for test stimulation by a high-volume provider were overall 2.7 times as likely to proceed to IPG implant as those who had their lead placement by a low-volume provider. This could be due to one of many possible factors. It is possible that high-volume providers achieve a better response owing to surgical technique that maximizes patient response, resulting in a better outcome. The clinical characteristics of patients seen by high-volume providers may also be different and more favorable for a positive outcome with sacral neuromodulation. Alternatively, high-volume providers may be more likely to proceed to stage II in patients whose response is borderline, thereby increasing the rate of battery placement without necessarily having better surgical technique over lowvolume providers. However, our results could have also been partly due to physician learning curve. In Medicare, physicians in the lower three quartiles did fewer than 5 procedures in 11 years. They may have still been in the learning curve, which may have contributed to the outcomes we observed.

Patients who underwent lead placement by a urologist were more likely to proceed to battery placement. We previously examined the provider-specialty relationship in sling surgery for stress incontinence, and found that patients who underwent a sling by a gynecologist had a lower rate of re-operation for prolapse within one year of the sling (12). This was due to the fact that gynecologists were more likely to perform concomitant prolapse surgery at the time of the sling. The provider-specialty relationship is more diffi- cult to define with sacral neuromodulation, as conversion rate, as defined by permanent IPG placement, is a function of subjective surgeon and patient decision-making. The majority of lead placements were performed by urologists. The fact that outcomes were better among urologists may be due to that fact that there were more high-volume providers among urologists than gynecologists. The differences in outcomes between specialties, if real, will likely diminish as sacral neuromodulation spreads throughout the gynecologic community.

Female patients had better outcomes than men. A relationship between patient gender and outcomes of sacral neuromodulation has been found in previous case series (18), but this finding is not consistent in the literature (19). It may be that urge incontinence and other voiding disorders are more difficult to treat in men, possibly relating to the long-term effects of prostatic obstruction on the bladder. Patients with OAB-wet had better outcomes than those with $O A B-d r y$, a finding that has been supported in clinical series (20). Overall rates of IPG implantation were much lower than observed in published clinical series. This suggests that real-world outcomes are inferior to those of experts in the field who publish such series (18-22). The main reason for not progressing to IPG placement is a suboptimal response in the test phase. This may be technical, in that the lead or wire is in a suboptimal location; it might be due to surgeons' accepting only partial responses in the operating room, rather than attempting to get all three responses (levator bellows, toe response, and sensation) in all four leads; or it may be due to patient selection in which patients do not respond despite optimal intraoperative responses. Our findings may therefore give more accurate information to providers so that patients can be counseled with realistic expectations when proceeding with InterStim.

In addition, IPG implantation was higher in the groups who underwent formal stage I placement of the lead. This finding correlates with clinical series in the literature (18-22). The most likely explanation is the fact that the percutaneous wire may easily migrate after the percutaneous trial. However, other unmeasurable factors could account for the decision to proceed with IPG implantation. For example, providers and patients may feel more investment in proceeding to IPG implantation after formal stage I testing, leading to a higher rate of IPG placement. A related issue is that percutaneous testing is less invasive, so it may be offered to (and accepted by) patients who are not as bothered by their symptoms 
and/or not as motivated to intervene, compared with patients who undergo stage I. Regardless, the poor conversion rate of percutaneous trials leads us to question their use over formal lead placement. The fact that younger age predicted better outcomes after formal stage I placement but not percutaneous testing may also reflect the inaccuracies of percutaneous testing.

Claims-based data provide knowledge about real-world practice patterns and outcomes. However, such data have inherent limitations that relate to the lack of clinical information present. We were not able to assess the degree of success among patients, but rather were confined to measuring conversion rate by IPG placement. Claims data do not give any clinical information about patient symptom reduction, and patients can have devices implanted that are ineffective. Though lead placement is often considered successful, and a battery is implanted if a patient is improved by $50 \%$ or more (21), there is tremendous variation in how improvement is measured objectively by the physician and subjectively by the patient. In addition, gynecologists are more likely to treat women (though some do perform neuromodulation on men, which could have impacted our gender-specific findings). Lastly, the Medicare population is older, and may not reflect the entire population of patients undergoing sacral neuromodulation.

\section{CONCLUSION}

Conversion rate of sacral neuromodulation, as defined by implantation of a permanent IPG, was greater among high-volume providers and urologists. This suggests that technical factors, including the use of an operative (staged) testing approach, play a role in improving outcomes. Although women had better outcomes than men, there was variation in outcomes by patient age and diagnosis. Further research may better define the relationship between outcomes of sacral neuromodulation and specific etiology of voiding dysfunction.

\section{Authorship Statement}

All authors were involved in the research design, data analysis, drafting, and critical review of the paper, and approval of the submitted version.

\section{How to Cite this Article:}

Anger J.T., Cameron A.P., Madison R., Saigal C., Clemens J.Q.; Urologic Diseases in America Project. 2014. Predictors of Implantable Pulse Generator Placement After Sacral Neuromodulation: Who Does Better? Neuromodulation 2014; 17: 381-384

\section{REFERENCES}

1. Birkmeyer JD, Stukel TA, Siewers AE, Goodney PP, Wennberg DE, Lucas FE. Surgeon volume and operative mortality in the United States. N Engl J Med 2003;349:21172127.

2. Begg CB, Cramer LD, Hoskins WJ, Brennan MF. Impact of hospital volume on operative mortality for major cancer surgery. JAMA 1998;280:1747-1751.

3. Edwards EB, Roberts JP, McBride MA, Schulak JA, Hunsicker LG. The effect of the volume of procedures at transplantation centers on mortality after liver transplantation. N Engl J Med 1999;341:2049-2053.

4. Hannan EL, O'Donnell JF, Kilburn H Jr, Bernard HR, Yazici A. Investigation of the relationship between volume and mortality for surgical procedures performed in New York State hospitals. JAMA 1989;262:503-510.
5. Hu JC, Gold KF, Pashos CL, Mehta SS, Litwin MS. Role of surgeon volume in radical prostatectomy outcomes. J Clin Oncol 2003;21:401-405.

6. Ellison LM, Heaney JA, Birkmeyer JD. The effect of hospital volume on mortality and resource use after radical prostatectomy. J Urol 2000;163:867-869.

7. Begg CB, Riedel ER, Bach PB et al. Variations in morbidity after radical prostatectomy. N Engl J Med 2002;346:1138-1144.

8. Yao SL, Lu-Yao G. Population-based study of relationships between hospital volume of prostatectomies, patient outcomes, and length of hospital stay. J Natl Cancer Inst 1999;91:1950-1956.

9. Dimick JB, Goodney PP, Orringer MB, Birkmeyer JD. Specialty training and mortality after esophageal cancer resection. Ann Thorac Surg 2005;80:282-286.

10. Goodney PP, Lucas FL, Stukel TA, Birkmeyer JD. Surgeon specialty and operative mortality with lung resection. Ann Surg 2005;241:179-184.

11. McKenna DB, Marioni JC, Lee RJ, Prescott RJ, Doherty VR. A comparison of dermatologists', surgeons' and general practitioners' surgical management of cutaneous melanoma. Br J Dermatol 2004;151:636-644.

12. Anger JT, Litwin MS, Wang Q, Pashos CL, Rodriguez LV. Variations in stress incontinence and prolapse management by surgeon specialty. $J$ Urol 2007;178 (4 Pt 1):1411-1417.

13. Cameron AP, Anger JT, Madison R, Saigal CS, Clemens JQ. National trends in the usage and success of sacral nerve test stimulation. J Urol 2011;185:970-975.

14. Brandeis J, Pashos CL, Henning JM, Litwin MS. A nationwide charge comparison of the principal treatments for early stage prostate carcinoma. Cancer 2000;89:17921799.

15. Saigal CS, Pashos CL, Henning JM, Litwin MS. Variations in use of imaging in a national sample of men with early-stage prostate cancer. Urology 2002;59:400-404.

16. Baron JA, Lu-Yao G, Barrett J, McLerran D, Fisher ES. Internal validation of Medicare claims data. Epidemiology 1994;5:541-544.

17. Cameron AP, Anger JT, Madison R, Saigal CS, Clemens JQ; Urologic Diseases in America Project. Battery explantation after sacral neuromodulation in the Medicare population. Neurourol Urodyn 2013;32:238-241.

18. Amundsen $\mathrm{CL}$, Romero AA, Jamison MG, Webster GD. Sacral neuromodulation for intractable urge incontinence: are there factors associated with cure? Urology 2005;66:746-750

19. Koldewijn EL, Rosier PF, Meuleman EJ, Koster AM, Debruyne FM, van Kerrebroeck PE. Predictors of success with neuromodulation in lower urinary tract dysfunction: results of trial stimulation in 100 patients. J Urol 1994;152 (6 Pt 1):2071-2075.

20. van Kerrebroeck PE, van Voskuilen AC, Heesakkers JP et al. Results of sacral neuromodulation therapy for urinary voiding dysfunction: outcomes of a prospective, worldwide clinical study. J Urol 2007;178:2029-2034.

21. Herbison GP, Arnold EP. Sacral neuromodulation with implanted devices for urinary storage and voiding dysfunction in adults. Cochrane Database Syst Rev 2009;(2)CD004202.

22. Leong RK, De Wachter SG, Nieman FH, de Bie RA, van Kerrebroeck PE. PNE versus 1st stage tined lead procedure: a direct comparison to select the most sensitive test method to identify patients suitable for sacral neuromodulation therapy. Neurourol Urodyn 2011;30:1249-1252.

\section{COMMENT}

In this study based on a sample survey of Medicare claims, the rate of IPG implantation following a screening trial was shown to be higher among "high volume providers". High volume was defined as implanters having performed 5 or more procedures over a ten year period, which obviously does not guarantee proficiency. Furthermore, the authors are correct to point out that the decision to proceed to an implant may be variable and subjective, and the "conversion rate" does not equal success of the therapy. Still, the rate of conversion was found to be higher after a staged trial and for patients with wet versus dry $O A B$. Both of these observations correlate with clinical series in the literature, underscoring the potential soundness of the methodology. A future survey conducted over a time period exclusively using modern techniques (tined-lead, fluoroscopic guidance, minimal anesthesia), with a more experienced surgeon base, and with more attention to measures that define post-implant success of the therapy could lead to more meaningful conclusions.

Steven Siegel, MD Woodbury, MN, USA

Comments not included in the Early View version of this paper. 